\title{
When Technology Meets the Mind: A Comparative Study of the Technology Acceptance Model
}

\author{
Lucy Dadayan ${ }^{1}$, Enrico Ferro $^{2}$ \\ ${ }^{1}$ School of Information Science and Policy, State University of New York \\ Room 113, Draper Hall, 135 Western Avenue, Albany, NY 12222 \\ ld8318@albany. edu \\ ${ }^{2}$ Istituto Superiore Mario Boella (ISMB) \\ Via Boggio 61, 10138 Turin, Italy \\ ferrodismb.it \\ www.enricoferro.com
}

\begin{abstract}
Issues related to technology, including diffusion, acceptance, adoption, and adaptation, have been the focus of research for different disciplines including Information Systems (IS), System Dynamics, Psychology, and Management Science. Of all research conducted and models developed to study technology related issues, the Technology Acceptance Model (TAM) stands out as most prominent, particularly in the field of IS. However, technology acceptance research has been relatively limited in its application to the public sector. Therefore, there is a concurrent need to develop and gain empirical support for models of technology acceptance within the public sector, and to examine technology acceptance and utilization issues among public employees to improve the success of IS implementation in this arena. In this paper we present a more comprehensive, yet parsimonious model of technology acceptance and suggest testing it both in public and private sectors to help understand the similarities and differences (if any) between the two sectors.
\end{abstract}

\section{Introduction}

In the last decade, a considerable amount of financial resources have been allocated to the implementation of e-Government projects. In the early years, projects primarily had a technological focus. This was due to the belief that organizations' behaviour and performance could be changed and improved by simply infusing technology. Over the years, the high rate of IT project failures prompted many to acknowledge the limits of this approach. The interaction between people and technology is a complex phenomenon involving rational as well as emotional factors. Failing to acknowledge the importance of understanding the underlying attributes of human-computer interaction may jeopardize the success of IT projects in e-Government. Recently, both academicians and practitioners have turned their attention to the organizational aspects of IT projects. And while the process of technology acceptance has been widely studied in the private sector, it has been relatively overlooked in the e-Government field. This paper 
attempts to fill a gap in the literature by deepening the understanding related to technological acceptance issues among public sector employees.

\section{Objectives}

The main objective of the study is to investigate the process of technology acceptance in the public sector, which will help both policy makers and practitioners gain a better understanding of the key factors driving the diffusion of information and communication technologies among public organizations. The long-term goal of our study is to contribute and improve the design of the policies aimed at fostering the adoption, acceptance and usage of Internet based technologies at all levels of public administration.

We will present the results stemming from the first phase of the study in this paper. In particular, we will propose an extended version of the TAM accounting for a wider range of contextual and individual factors.

In the second phase of the study, the application of the suggested model to both public and private context will highlight the similarities and differences of the technology acceptance process. The results of the research will allow stimulating discussion on whether and how public employees differ from private employees in their behaviour toward technology acceptance and usage.

\section{Literature Review}

In 1986, Fred Davis developed the TAM foundation to explain how and when users decide to accept and use a technology. The main elements of Davis's TAM model are "perceived usefulness" and "perceived ease of use." The model suggests that when users are presented with a new software package, "perceived usefulness" and "perceived ease of use" influence their decisions about how and when they will use the new software. Recently, numerous studies have been conducted using the original TAM - or an extended version of TAM - to examine the usage of IT. For example, Davis, Bagozzi, and Warshaw (1989) examined an intention model called the Theory of Reasoned Action (TRA) with TAM to discover "synthesizing elements of the two models in order to arrive at a more complete view of the determinants of user acceptance." Taylor and Todd (2001) extended, integrated, and compared the TAM model with two variations of the Theory of Planned Behaviour (TBP) to determine which model is the most helpful in understanding the technology usage. Venkatesh, Morris, Davis, and Davis (2003) extended TAM, building a new model called Unified Theory of Acceptance and Use of Technology (UTAUT), which helps managers assess the likelihood of technology success as well as understand the drivers of technology acceptance.

The literature review shows that there are many attempts to evaluate, integrate, and extend different models and approaches for analyzing the implications of the TAM 
theory. Different researchers have adopted different measures for technology in order to understand its usage. The different measurement criteria for evaluating technology usage included looking at technology as an entertainment tool (on-line games), a taskoriented tool (software for increasing organization productivity), a learning tool (software for school purposes), and an information-seeking tool (Internet). The unit of analysis in most of these studies was individual users, and their usage of technology was based mainly on individual motivations and individual decision-making processes. These past studies are deductive in nature, as they are all based on an existing TAM theory and pre-established research hypotheses. Most of the past studies adopted quantitative research to test the hypotheses and evaluate the TAM theory. The contribution of the past research studies are the revisions and extensions of TAM theory to explain the usage of different technological tools. The main limitation of these studies is that the sample of the research does not allow generalizing the findings to broad sectors of technology users in general and public sector employees in particular.

\section{The Research Study}

The proposed research model draws its theoretical premises from TAM (Davis 1989; Davis et al. 1989) and UTAUT (Venkatesh et al. 2003), and adopts the technology acceptance framework proposed by $\mathrm{Hu}$ et al. (1999) and Chau and $\mathrm{Hu}$ (2002).

$\mathrm{Hu}$ et al. (1999) stated that technology acceptance should be examined in three different contexts: individual, technological, and implementation. Therefore, an individual's acceptance behaviour is influenced by factors pertaining to the individual context, the technological context, and the implementation context (Chau and Hu, 2002). Individual context refers to the characteristics of individual end-users; the technological context refers to the characteristics of the technology such as functionality and user-friendliness, among others; and implementation context refers to the user's professional environment. Chau and Hu's (2002) multi-contextual framework is adapted for this research because of its applicability to technology acceptance within both the public and private sectors.

The proposed research will study the impact of the following factors on employees' attitudes toward technology acceptance motivation, usage intention, and actual usage: (1) technology performance expectancy, (2) technology effort expectancy, (3) compatibility, (4) social influences, (5) organizational facilitating conditions, (6) computer attitude, and (7) computer anxiety. The significance of this study is that it is a comparative study using a research model that includes a sample of both private and public sector employees, to extend technology acceptance research into the public sector. In addition, the study sample will consist of both public and private employees representing two different industries: education and health. The results of this study will have both practical and theoretical applications for stakeholders involved in public and private sectors. 


\subsection{The Modified Research Model}

The research model for the proposed study is based on the modification and extension of TAM and UTAUT (see Figure 1 below for the proposed research model diagram). The research model was pilot-tested and based on interviews of ten New York State government employees representing different industries, including health and education. The research model was finalized based on pilot study results.

As shown in Figure 1 below, the research model incorporates Chau and Hu's (2002) three dimensions. As the research model diagram shows, the technological context includes two determinants - performance expectancy and effort expectancy. Previous studies of technology acceptance show that performance expectancy is a strong predictor of technology acceptance intentions (Davis, Bagozzi, and Warshaw 1992; Taylor and Todd 2001; Venkatesh and Davis 2000; Venkatesh et al. 2003). Although the Venkatesh et al. (2003) study shows that effort expectancy does not have significant impact on behavioural intentions; it is included in the model to empirically validate the significance of effort expectancy on technology usage intentions.

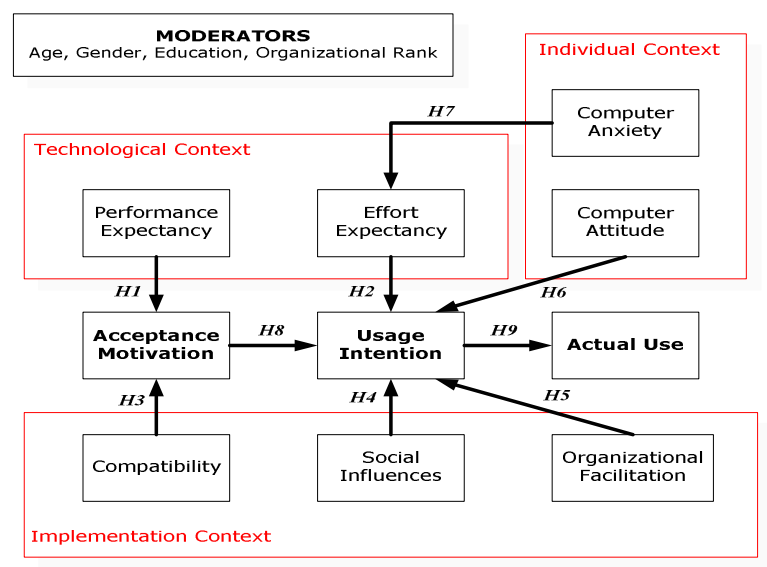

Fig. 1. Research Model

The implementation context includes three determinants - compatibility, social influence, and organizational facilitation. Compatibility is not included as a separate determinant of technology acceptance and usage either in TAM or UTAUT. However, compatibility has been included as a separate measurement for the technology acceptance study conducted by Chau and $\mathrm{Hu}$ (2002), where the authors found a significant relationship between compatibility and perceived usefulness of technology. This study will test the impact of compatibility on technology acceptance motivation. Social influence is included as a separate determinant in the UTAUT, as previous technology acceptance studies found a direct impact of social influence on behavioural intentions (Karahanna, Straub and Chervany 1999; Venkatesh and Davis 2000). We will test the impact of effort expectancy on technology usage intentions. The empirical results from 
UTAUT show that organizational facilitating conditions do not play a significant role in predicting behavioural intentions, but there is a statistically significant relationship between the organizational facilitating conditions and the actual usage of technology (Venkatesh et al. 2003). The organizational facilitating conditions construct is included in the proposed study to test the significance of organizational facilitating conditions.

Individual context includes two determinants: computer attitude and computer anxiety. Chau and Hu's (2002) study shows that the attitude toward computers plays a significant role in the technology acceptance decisions. As supported by UTAUT, computer anxiety has a direct effect on effort expectancy. The proposed study will empirically validate the impact of computer attitude on technology usage intentions, as well as test the relationship between the computer anxiety and effort expectancy.

\subsection{Research Hypotheses}

The following hypothesized relationships will be tested:

H1: The higher the perceived performance expectancy of technology, the more motivated the employees are to accept technology.

H2: The higher the perceived effort expectancy of technology, the lower the employees' technology usage intentions are.

H3: The higher the technology compatibility level within the agency, the more motivated the employees are to accept technology.

H4: The stronger the social influences in a government agency, the higher the employees' technology usage intentions are.

H5: The stronger the organizational facilitating conditions, the higher the employees' technology usage intentions are.

H6: Computer attitude will have a positive effect on technology usage intention.

H7: Computer anxiety will have a positive impact on effort expectancy.

H8: There will be a positive relationship between technology acceptance motivation and usage intentions.

H9: There will be a positive relationship between the usage intentions and actual usage of technology.

\subsection{Conceptualization of Variables}

The measurement criteria for evaluating acceptance motivation and usage intention of technology will view technology as a communication tool for increasing organization productivity. Technology acceptance motivation and usage intention will be employed as two dependent variables for this study. Acceptance motivation is the degree to which a person believes that using particular software will be rewarding in terms of professional productivity (job performance) and promotions. Usage intention is measured based on the purpose of using particular software. The independent variables for 
this study will be the performance expectancy, effort expectancy, compatibility, social influence, organizational facilitating conditions, computer attitude, and computer anxiety. Performance expectancy is defined as the degree to which an employee believes that using technology will help him or her to achieve better job performance (adopted from Venkatesh et al. 2003). Effort expectancy is defined as the degree of ease of technology use (adopted from Venkatesh et al. 2003). Compatibility is the degree to which technology is perceived as being consistent with the existing practices, values, norms, needs, and experiences of the employees (adapted from Chau and $\mathrm{Hu}$ 2002). Social influence is the degree to which an employee perceives that others (e.g., coworkers) believe he or she should use a technology. Organizational facilitating conditions measure the degree to which an employee perceives that an organizational and technical infrastructure exists to support use of the technology (adapted from Venkatesh et al. 2003). Computer attitude is defined by the degree to which individuals like and feel comfortable when using computers. Previous studies developed the Computer Attitude Scale (Loyd and Gressard, 1984), which is adapted to study attitudes toward statistical software. Computer anxiety is the degree of fear or apprehension felt by individuals when they use computers, or when they consider the possibility of computer utilization (Henerson, Morris, and Fitz-Gibbon, 1978). This definition is based on Simonson, Maurer, Montag-Torardi, and Whitaker's (1987) development of the Computer Anxiety Index. Four control variables will be included in this study: age, gender, educational background, and organizational rank (state grade) of the employees.

\section{Research Methodology}

During the second phase of the research, a multi-method technique will be employed to collect substantial qualitative, quantitative, and longitudinal data to study technology acceptance and utilization in public and private sector employees. Qualitative research methods are noticeably infrequent in technology acceptance research. Thus, the combination of both quantitative and qualitative methods, as opposed to only quantitative, is a significant methodology consideration (Kaplan and Duchon 1988). Qualitative data underline the importance of context, people, and organizational issues in technology use and acceptance, and provide a deeper understanding of what is actually happening. Moreover, qualitative data help to understand the dynamic interaction between the constructs, which may change over time.

We will evaluate the acceptance motivation, usage intention, and Intranet use among public and private sector employees. For this study we chose the Intranet rather than other software applications, as its use is appropriate and equally applicable to the private and public sectors, as well as the health and education industries. In addition, the Intranet is a powerful tool that allows the obtaining and sharing of documents, web pages, and calendars, scheduling meetings, managing and delegating action items and project tasks, all of which are important and necessary for effective and efficient communication among employees. Moreover, as virtual work becomes increasingly more widespread, it is crucial that employees are able to utilize the Intranet. 
Employees are the unit of analysis for this study. . Our research will be based on the triangulation of multiple data sources and data analysis methods, including semistructured interviews and an online survey questionnaire. Although the survey will serve as the primary data collection method, the interviews will provide complementary data and will help to refine the research model and hypotheses.

We will collect data in three phases. In the first phase we will collect qualitative data through semi-structured interviews, which will help to revise the research model and survey questionnaire. In the second phase, we will collect quantitative data that will help to study the acceptance motivation and usage intentions of Intranet among employees at different agencies. Finally, in the third phase we will employ a longitudinal multi-method study to evaluate the actual usage of the Intranet. The proposed timeframe for data collection will span a one-year period, with two months for phase one interviews, three months for phase two surveys, and seven months for longitudinal study.

\section{Limitations}

There are a number of limitations for this research study. First, the study sample consists of employees representing two major industries: education and health. This sample group limits the generalization ability of the results to agencies in other industries. The second limitation is the limited measurement criteria for assessing the usage of technology as a communication tool only (usage of Intranet). However, the research could be expanded by assessing technology usage as a task-oriented, information seeking tool, and interactive task management tool.

\section{Conclusions and Expected Results}

In this paper we presented the first phase of the project, which is aimed at studying and comparing the process of technology acceptance in public and private sectors. An analysis of the literature heretofore published showed that despite previous studies to evaluate, integrate, and extend different models and approaches for analyzing the implications of the TAM theory, employees of public sector agencies have seldom been the unit of analysis. Business managers and students have been the traditional subjects of technology acceptance and usage research. The strength of the proposed study is that its subjects comprise both public and private sector employees, allowing a comparative analysis of research results. Most of the past studies are deductive in nature and based on an existing TAM theory. They adopt quantitative research to test pre-established research hypotheses and evaluate the TAM theory. Therefore, the collection of qualitative and quantitative data will increase the robustness of results by permitting data triangulation and providing a deeper understanding of what the driving force is for technology acceptance and usage among state government agencies, as well as private agencies. The study will also allow comparing and contrasting technol- 
ogy acceptance and usage practices across two different industries, i.e., education and health, which have different missions.

An extension of TAM has also been proposed. In the new formulation of the model, a wider range of contextual and individual factors has been included. The extension is intended to provide a more comprehensive representation of the phenomenon studied without compromising the model's cost-effectiveness.

In conclusion, our study will attempt to fill an important gap currently present in eGovernment literature. Gaining a deeper understanding of how the government employees differ from those in the private sector-in terms of acceptance and adoption of technology - could result in a faster and more efficient diffusion of eGovernment activities. The ability to design ad hoc policies, taking into account the specificities present among public employees surely represents a step forward toward improving the low success rates currently experienced by e-Government public managers worldwide.

\section{References}

1. Chau, P. and Hu, P.: Examining a Model of Information Technology Acceptance by Individual Professionals: An Exploratory Study. Journal of Management Information Systems, Vol. 18. (2002) 191-229

2. Davis F.: Perceived Usefulness, Perceived Ease of Use, and User Acceptance of Information Technology. MIS Quarterly, Vol. 13. (1989) 318-341

3. Davis F., Bagozzi R., and Warshaw P.: User Acceptance of Computer Technology: A Comparison of Two Theoretical Models. Management Science, Vol. 8. (1989) 982-1003

4. Davis F., Bagozzi R., and Warshaw P.: Extrinsic and Intrinsic Motivation to Use Computer in the Workplace. Journal of Applied Social Psychology, Vol. 22. (1992) 1111-1132

5. Henerson, M., Morris, L., and Fitz-Gibbons, C.: How to Measure Attitudes. Sage Publications Inc, Thousand Oaks, CA (1978)

6. Hu, P., Chau, P., Liu Sheng, O. R. and Tam, K.: Examining the Technology Acceptance Model Using Physician Acceptance of Telemedicine Technology. Journal of Management Information Systems, Vol. 16. (1999) 91-112

7. Kaplan, B. and Duchon, D.: Combining Qualitative and Quantitative Methods in Information Systems Research: A Case Study. MIS Quarterly, Vol. 12. (1988) 570-586

8. Karahanna, E., Straub, D. and Chervany, N. L.: Information Technology Adoption Across Time: A Cross-sectional Comparison of Pre-adoption and Post-adoption Beliefs. MIS Quarterly, Vol. 23. (1999) 83-204

9. Loyd, B., and Gressard, C.: Reliability and Factorial Validity of Computer Attitude Scales. Educational and Psychological Measurement, Vol. 44. (1984) 501-505

10. Simonson, M., Maurer, M., Montag-Torardi, M., and Whitaker, M.: Development of a Standardized Test of Computer Literacy and A Computer Anxiety Index. Journal of Educational Computing Research, Vol. 3. (1984) 231-247

11. Taylor, S. and Todd, P.: Understanding Information Technology Usage: A Test of Competing Models. Information Systems Research, Vol. 6. (2001) 144-176

12. Venkatesh, V. and Davis, F.: A Theoretical Extension of the Technology Acceptance Model. Management Science, Vol. 46. (2000) 186-204

13. Venkatesh, V., Morris M., Davis G., and Davis F.: User Acceptance of Information Technology: Toward a Unified View. MIS Quarterly, Vol. 27. (2003) 425-479 